\title{
Assessment of Hazard Analysis Critical Control Point (HACCP) of Fast Food (Momo) from Restaurants of Kathmandu City
}

\author{
Poonam Thapa $^{1}$, Anjana Singh ${ }^{1}$ and Tika Bahadur Karki ${ }^{2}$ \\ ${ }^{1}$ Central Department of Microbiology, Tribhuvan University, Kirtipur, Kathmandu \\ ${ }^{2}$ Department of Food Technology and Quality Control, Babarmahal, Kathmandu \\ e-mail :anpoonam@gmail.com
}

\begin{abstract}
Hazard analysis critical control point (HACCP) module was prepared for one of the most popular fast food momo (chicken momo and buff momo). For this, hazard analysis was conducted in eight different restaurants of Katmandu city by observing all the steps of preparation, monitoring time-temperature throughout the preparation process and collecting samples of different stages of these food. The samples were assessed for total aerobic mesophilic count (TAMC), total coliform count, total Staphylococcus aureus count, total yeast and mold count, detection of Salmonella spp. and Escherichia coli. During preparation of chicken momo, the highest TAMC, yeast and mold count, coliform and $S$. aureus count were found to be $2.8 \times 10^{6} \mathrm{cfu} / \mathrm{g}, 2.1 \times 10^{3} \mathrm{cfu} / \mathrm{g}, 1.92 \times 10^{5} \mathrm{cfu} / \mathrm{g}$ and $3.4 \times 10^{3} \mathrm{cfu} / \mathrm{g}$ respectively. While preparation of buff momo, the highest TAMC, yeast and mold count, coliform count and S. aureus count were found to be $2.82 \times 10^{6} \mathrm{cfu} / \mathrm{g}, 1.9 \times 10^{3} \mathrm{cfu} / \mathrm{g}, 2.1 \times 10^{5} \mathrm{cfu} / \mathrm{g}$ and $2.8 \times 10^{3} \mathrm{cfu} / \mathrm{g}$ respectively. These values and near to these values too were obtained from the samples of pickles, spices, raw momo, mixture of minced meat with spices and raw meat. The organisms originally present in the raw materials were subsequently transmitted to all the preparatory stages but was not observed after steaming and hence the final steamed product of both kinds of momo were free from microorganisms. Thus from the above findings, it was concluded that steaming was the main critical control point (CCP), which if done for proper time and temperature, can eliminate all the contaminating organisms.
\end{abstract}

Key words: coliform count, critical control point, hazard analysis, Staphylococcus aureus, Escherichia coli, Salmonella spp.

\section{Introduction}

Every developing country in the world, today, is witnessing the phenomena of rural-to-urban migration mainly due to the well accepted notion that opportunities are plenty in the cities to carve a better life. Kathmandu valley, too, is heading towards rapid urbanization and hence, acutely displays the migration syndrome. This migration syndrome demands to feed a swelling population is one amongst the many. Moreover, with ample international exposure, the eating habits and tastes of people have also come to vary which has further influenced the emergence of numerous restaurants catering to global tastes and cuisines. Hence, there is an urgent need to know the quality of food that is provided in the food establishments.

Microorganisms enter the food by raw ingredients, water, environmental cross contamination, inadequate sanitation and poor handling practices during cooking and serving. Certain microbial contamination of food is an indicator of poor sanitary practice in the preparation and storage of foods. Mishandling in food service establishments can contribute significant 
outbreak of food-borne diseases (Frazier \& Westhoff 2001).

Microbial examination of final product does not reveal information of the point of contamination nor ensures protection against it but only gives the idea of hazard quality. For this reason, the traditional approach of the hygiene supervision is not quite effective and is replaced by a more programmatic approach focused on the control of factors threatening the wholesomeness already during the production process (Jay 1992).

A relative new concept has developed known as hazard analysis critical control point (HACCP) which is a scientific and systematic approach of identification, assessment and control of hazardous pathogens (Buchanan et al. 1998). The system seeks to identify the hazards associated with any stages of food production, processing or preparation, assesses the related risks and determines the operation where control procedures will be effective (Peter et al. 2000). Thus, the central feature of HACCP is the determination of the CCPs which is an operation (practice, procedure, location or process) at which control can be exercised over one or more factors to eliminate, prevent or minimize a hazard to ensure the safety of products.

The HACCP concept was originally proposed for the food processing industry. However, available surveillance data suggest that the incidence of food borne disease outbreaks caused by mishandling of foods is actually higher in food service establishments and at the consumer level than in the food processing industry. Therefore, the HACCP concept has been extended to food service establishments (Bryan 1981). The benefits include the enhanced food safety and more timely response to problems (FDA 2005).

Dumplings (momos) are popular in Nepal, Sikkim and Tibet. Momos are made of simple flour and water dough; white flour is generally preferred and sometimes a little yeast or baking soda is added to give a more doughy texture to the finished product. The filling may be one of the several mixtures of minced buff/ pork/ chicken/ or vegetables with any or all of the following: onions, shallots, garlic and cilantro/coriander. The mixture is usually spiced with salt, pepper and often ground cumin. This meat mixture is wrapped in a circular sheet of elastic dough into a fashionable ball and is steamed for 10-15 minutes before serving hot with soup and pickle.

The main purpose of this study was to analyze the hazards associated with momo, one of the common menu items of each and every fast food restaurants and determine its critical control points (CCPs). For the determination of CCPs, samples were collected from different stages of momo preparation to determine the sources of contamination. Similarly the analysis was done in raw materials, final products and its subsequent stages.

\section{Methodology}

The study was conducted in eight different restaurants of Kathmandu city from April 2005 to November 2005. The restaurants were randomly selected. Field observation and interview with the owner and workers of the restaurants via structured questionnaire were carried out to get the basic information on handling procedure and hygienic practices.

The main purpose of the study was to analyze the hazards associated with restaurant foods and determine its critical control points (CCPs). For the determination of CCPs, samples were collected from different stages of food preparation to determine the sources of contamination. The whole momo preparation process was observed and different preparatory stages of buff momo and chicken momo (raw meat, mixture of minced meat with spices, raw momo, spices, flour, steamed momo, water) as well as the pickles served with that cuisine were aseptically collected. During sampling, temperature of the food was measured and time too was subsequently observed. The samples were then collected in sterile plastic bags and placed immediately in an insulated container with ice and taken to the Central Food Research Laboratory, Babar Mahal, Kathmandu as soon as possible and processed on the same day or samples were preserved overnight and processed next day. During the study, total aerobic mesophilic bacterial load, total coliform load, total staphylococcal load, total yeast and mold load were determined. In addition, presence of Escherichia coli, Salmonella spp. and Staphylococcus aureus was also determined. 


\section{Description of buff momo and chicken momo preparation}

Raw buff/ chicken meat receiving

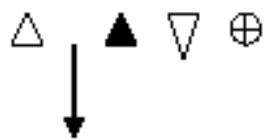

Frozen $\left(-18^{\circ} \mathrm{C}\right.$ until mixed $)$
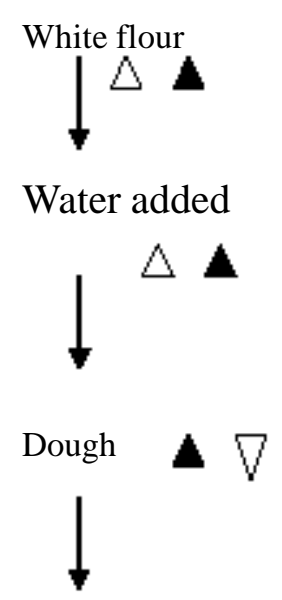

Oil added<smiles>C[13CH3]</smiles>

Conditioned for (30-60 minutes)<smiles>[Te]</smiles>

Sheeted into circular discs<smiles>C[13CH2]</smiles>

onion, garlic, ginger (peeled)

$\otimes$

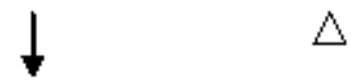

$$
\text { Chopped }
$$

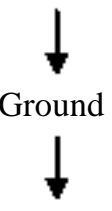

momo masala powder

paste \& kept at RT

$\oplus \mathrm{O}$

Tasting powder

alt

Added

and mixture prepared $\quad$

Small ball of meat mixture placed into circular dough sheet and packed by pleating peripheral edge to form momo

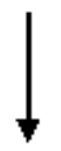

Steamed (66-72 ${ }^{\circ} \mathrm{C} / 10-15$ minutes) whenever order

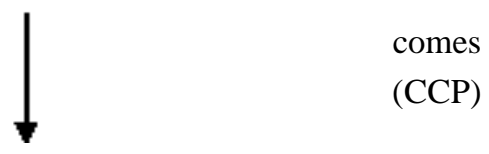

Served with tomato or sesame pickles 


\begin{tabular}{|c|c|}
\hline Symbols & Interpretation \\
\hline$\triangle$ & Possibility that food or water initially contaminated with food borne pathogens \\
\hline & $\begin{array}{l}\text { Possibility of contamination with food borne pathogens from surfaces or equipment in contact } \\
\text { with food }\end{array}$ \\
\hline & Possibility of contamination with food borne pathogens from persons who handle food \\
\hline & Direction of flow \\
\hline$(\mathrm{CCP})$ & Effective critical control point \\
\hline$\otimes$ & $\begin{array}{l}\text { Destruction of vegetative forms of bacteria if boiled or cooked to near boiling temperatures but } \\
\text { spore survive }\end{array}$ \\
\hline & Possibility of survival of microorganisms \\
\hline$\oplus$ & Possibility of multiplication (propagation) of bacteria \\
\hline
\end{tabular}

Since the samples were collected during different subsequent stages of chicken momo and buff momo preparations, the samples included for chicken momo were:

Sample P1= Raw chicken meat

Sample P2 = Mixture of minced chicken with spices

Sample P3= Raw chicken momo

Sample P4 = Steamed chicken momo

Sample P5 = Pickles

Sample P6 = Flour

Sample P7= Mixture of spices

The different samples taken from buff momo preparation were:

Sample P9= Raw buff meat

Sample P10 = Mixture of minced buff with spices

Sample P11= Raw buff momo

Sample P12F= Steamed buff momo

Sample P13 = Pickles
Sample P14 = Flour

Sample P15= Mixture of spices

The total aerobic mesophilic bacterial count, yeasts and molds count, total coliform count were performed by pour plate method with sterilized plate count agar, potato dextrose agar and violet red bile agar respectively, while $S$. aureus count was done by spread plate method by pouring sterilized mannitol salt agar. Similarly, detection of Salmonella spp. was done on brilliant green agar and xylose lysine deoxycholate agar and $E$. coli detection was done on eosin methylene blue agar. All the tests were performed by following Manuals of Food Quality Control (Refai 1979) and Microbiological Methods (Collins et al. 1989). Strict aseptic condition was maintained throughout the study. Quality of each test was maintained by using standard procedures. Sterility testing of each batch of culture and biochemical medium were checked by incubating one or two uninoculated tubes and plates of each lot with inoculated ones. Batch of the medium was discarded when uninoculated plates or tubes showed the growth of microorganism. During identification of organisms for each test, ATCC control positives and control negatives were taken simultaneously. 


\section{Results}

HACCP was conducted of the fast food momo (buff and chicken) from eight restaurants located at different places in Kathmandu city along with the surveillance study of those restaurants. The analysis of survey results showed that $62 \%$ of the restaurants studied had trained staff in sanitation while $38 \%$ of the restaurants had untrained staff. The survey results also showed that $25 \%$ of the restaurant had given health education to their staff only in training period, $13 \%$ of the restaurants had given health education to their staff when required and the rest had not trained working personnels in health education.

It was observed that unperishable raw materials were stored at room temperature while perishable items like, meat and other meat products such as mixture of minced meat with spices and pickles were stored in fridges. In all of the restaurants, pickles and ready to steam momo were prepared beforehand and kept in the fridge till the order came. Similarly, $62 \%$ of the working personnels seemed to take care about their personal hygiene while $38 \%$ did not.

The result from the table 2 showed that all of the samples of chicken momo from different restaurants analysed during the studies did not show the presence of Salmonella spp.
However, the samples analysed for the presence of $E$. coli showed the result that in restaurant of site B, $57 \%$ of the samples were contaminated with $E$. coli and the samples were P1, P2, P3 and P7. Similarly, restaurant of site $\mathrm{D}$ also had the same result while restaurants of site $\mathrm{C}$ and $\mathrm{G}$ had $71 \%$ of $E$. coli contamination in the samples P1, P2, P3, P6 and P7. But the restaurants of site A, E, F and $\mathrm{H}$ did not show the presence of $E$. coli in any of the samples.

In restaurants of site $\mathrm{A}, \mathrm{E}, \mathrm{F}$ and $\mathrm{H}$, the coagulase positive $S$. aureus isolated were $57 \%$ of the total samples. Similarly, in restaurants of site B and C the coagulase positive $S$. aureus isolated were $71 \%$ of the total samples while in restaurant of site D and G, the coagulase positive $S$. aureus isolated were $86 \%$ of the total samples.

The Table 3 results showed that all of the samples of buff momo from different restaurants analysed during the studies did not show the presence of Salmonella spp.

The samples analysed for the presence of E. coli showed the result that in the restaurant of site B, $57 \%$ of the samples were contaminated with $E$. coli and

\section{Identification of pathogenic micro-organisms}

Table 2. Identification of Salmonella species, Escherichia coli, coagulase positive Staphylococcus aureus in different stages of chicken momo preparation

\begin{tabular}{|c|c|c|c|c|c|c|c|}
\hline Restaurant & No. of samples & Salm & $a$ spp. & E. coli & & Coagulase $\mathrm{p}$ & aureus \\
\hline \multirow[t]{2}{*}{ Site A (Baneswor) } & 7 & $+\mathrm{ve}$ & $\%$ & + ve & $\%$ & $+\mathrm{ve}$ & $\%$ \\
\hline & & 0 & 0 & 0 & 0 & 4 & 57 \\
\hline Site B (Kalanki) & 7 & 0 & 0 & 4 & 57 & 5 & 71 \\
\hline Site C (Chabahil) & 7 & 0 & 0 & 5 & 71 & 5 & 71 \\
\hline Site D (Khichapokhari) & 7 & 0 & 0 & 4 & 57 & 6 & 86 \\
\hline Site E (Thamel) & 7 & 0 & 0 & 0 & 0 & 4 & 57 \\
\hline Site F (Maharajgunj) & 7 & 0 & 0 & 0 & 0 & 4 & 57 \\
\hline Site G (Balaju) & 7 & 0 & 0 & 5 & 71 & 6 & 86 \\
\hline Site H (Bhatbhateni) & 7 & 0 & 0 & 0 & 0 & 4 & 57 \\
\hline
\end{tabular}


Table 3. Identification of Salmonella species, Escherichia coli, and coagulase positive Staphylococcus aureus in different stages of buff momo preparation

\begin{tabular}{lccccccc}
\hline Restaurants & No. of samples & \multicolumn{2}{c}{ Salmonella spp. } & \multicolumn{2}{c}{ E. coli } & & \multicolumn{2}{c}{ Coagulase positive S. aureus } \\
\hline Site A (Baneswor) & 7 & $+\mathrm{ve}$ & $\%$ & $+\mathrm{ve}$ & $\%$ & $+\mathrm{ve}$ & $\%$ \\
\cline { 3 - 7 } & & 0 & 0 & 0 & 0 & 4 & 57 \\
Site B ( Kalanki) & 7 & 0 & 0 & 4 & 57 & 5 & 71 \\
Site C (Chabahil) & 7 & 0 & 0 & 5 & 71 & 5 & 71 \\
Site D (Khichapokahri) & 7 & 0 & 0 & 4 & 57 & 5 & 71 \\
Site E (Thamel) & 7 & 0 & 0 & 0 & 0 & 4 & 57 \\
Site F (Maharajgunj) & 7 & 0 & 0 & 0 & 0 & 4 & 57 \\
Site G (Balaju) & 7 & 0 & 0 & 5 & 71 & 6 & 86 \\
Site H (Bhatbhateni) & 7 & 0 & 0 & 0 & 0 & 4 & 57 \\
\hline
\end{tabular}

the samples were P9, P10, P11 and P15.Similarly, restaurant of site $\mathrm{D}$ also showed the same result while restaurants of site $\mathrm{C}$ and $\mathrm{G}$ had $71 \%$ of $E$. coli contamination in the samples P9, P10, P11, P14 and P15.

In the restaurants of site $\mathrm{A}, \mathrm{E}, \mathrm{F}$ and $\mathrm{H}$, the coagulase positive $S$. aureus isolated were $57 \%$ of the total samples. Similarly, in restaurants of site B, C and D the coagulase positive S. aureus isolated were $71 \%$ of the total samples while in

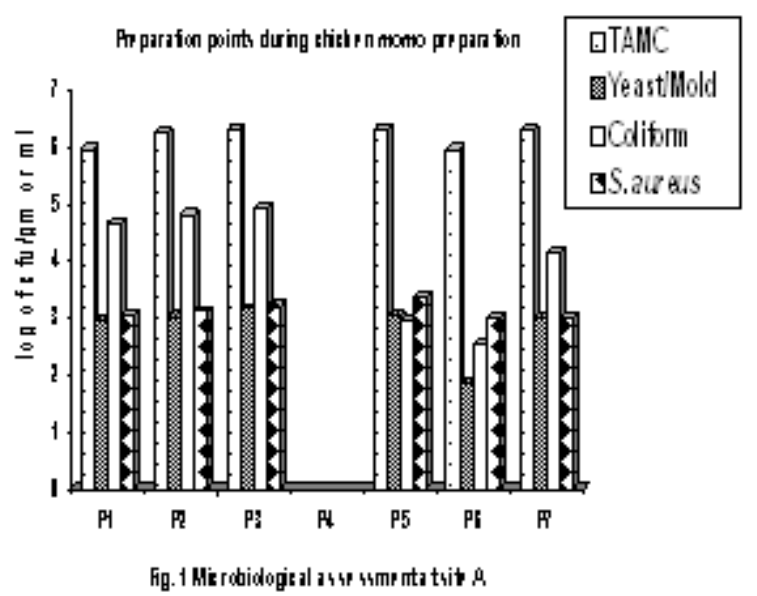

restaurant of site $\mathrm{G}$, the coagulase positive $S$. aureus isolated were $86 \%$ of the total samples.

The figures 1, 2, 3 and 4 describes the log of colony forming unit of total aerobic mesophilic count, total yeast and mold count, total coliform count and total $S$. aureus count of chicken momo and buff momo from restaurants of site A and site $G$ respectively with lower microbial count on site A and highest count on site $G$.

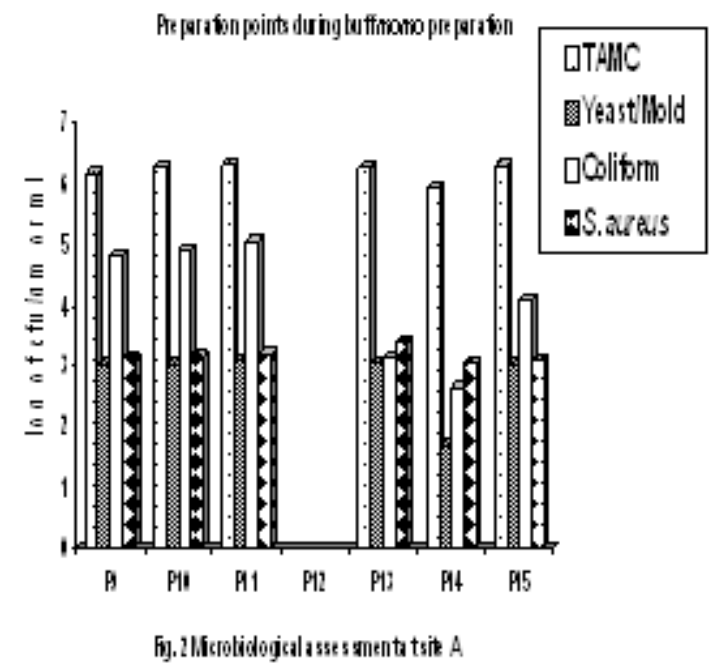



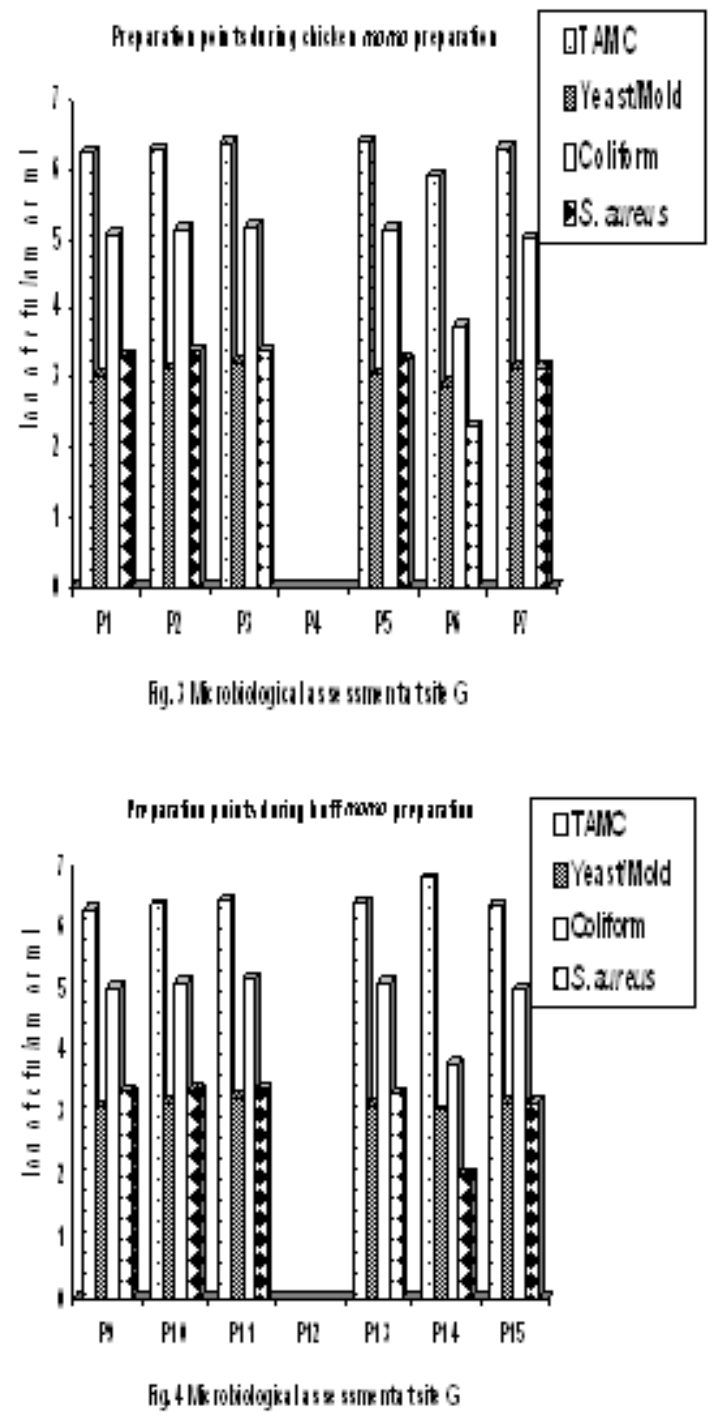

\section{Discussion}

Any food to be of good quality and safe for public health should be free from hazardous microorganisms (Freese et al.1998). So in order to fulfill this requirement in this study, the total aerobic mesophilic count, total coliform count, total yeast and mold count were performed along with the detection of some target pathogens like E. coli, Salmonella spp., S. aureus from samples taken from different preparation steps of chicken momo and buff momo.

The results obtained from the microbiological analysis assessed in seven key stages (raw meat, mixture of minced meat with spices, raw momo, steamed momo, pickles, flour, and mixture of spices) showed that, a considerably high levels of micro-organisms were observed throughout the various steps of both types of momo preparation process. The raw momo (sample P3 and P11) step being the major step, the highest microbial counts were observed. This is because the physical interventions like handling, cutting and mincing are even more serious and while mincing the contaminating bacteria on the surface are quickly dispersed through the whole mass. Moreover, the mincing process contributes to an increase in temperature which promotes faster bacterial growth (Anderson et al. 2000). Similarly, the raw momo (sample P3 and P11) is prepared with hands by mixing of minced meat with spices which can be the reason for the highest microbial count in raw meat and mixture of minced meat with spices.

During preparation of chicken momo, the highest aerobic mesophilic count, total yeasts and molds count, total coliform count and $S$. aureus count were found to be $2.8 \times 10^{6} \mathrm{cfu} / \mathrm{g}, 2.1 \times 10^{3} \mathrm{cfu} / \mathrm{g}, 1.92 \times 10^{5} \mathrm{cfu} / \mathrm{g}$ and $3.4 \times 10^{3} \mathrm{cfu} / \mathrm{g}$ respectively. These values and near to these values were obtained from the samples of pickles, spices, raw momo, raw meat and mixture of minced meat with spices. Similarly, during preparation of buff momo, the highest total aerobic mesophilic count, total yeasts and molds count, coliform count and $S$. aureus counts were found to be $2.82 \times 10^{6} \mathrm{cfu} / \mathrm{g}, 1.9 \times 10^{3} \mathrm{cfu} / \mathrm{g}, 2.1 \times$ $10^{5} \mathrm{cfu} / \mathrm{g}$ and $2.8 \times 10^{3} \mathrm{cfu} / \mathrm{g}$ respectively and these values too were from the samples such as pickles, spices, raw momo, mixture of minced meat with spices and raw meat.

After steaming, the quantitative results showed insignificant total plate count in both types of momo. Similarly, after steaming, the yeast and mold count, coliform count, $S$. aureus count were too reduced to $0 \mathrm{cfu} / \mathrm{g}$. This indicated that the time/temperature exposure for steaming $\left(66^{\circ} \mathrm{C}-72^{\circ} \mathrm{C}\right)$ for $10-15$ minutes was sufficient to reduce or kill the micro-organisms. Thus from the above studies, it can be concluded that the steaming/cooking is the CCP at which steamed or cooked for sufficient period of time-temperature can reduce the coliform organism to the levels independent of the quality of raw materials. So, if cooking is done for sufficient period of timetemperature, it fully eliminates the vegetative cells of harmful microbes. Thus, the result concluded that the final steamed product is safe for human consumption until and unless the serving plate and handling practices is good. 
The study also showed that samples P5 and P13 (pickles) were found to be heavily contaminated. The pickles made of tomato or sesame was prepared early in the morning in huge amount and was stored at refrigerator but during the lunch hour, it was displayed in the serving zone until finished without any protection which can be the possible reason for higher bacterial count. Moreover, when food is held, cooled, and reheated in a food establishment there is an increased risk from contamination caused by personnel, equipment, procedures, or other factors (Christopher 1999). So small batch preparation is an important tool for controlling bacterial growth because limiting the amount of food prepared minimizes the time the food is kept at a temperature that allows for growth.

Similarly, sample P7 and P15 (mixture of spices) too showed higher bacterial count because most of the grinder used for making the paste of spices were rarely cleaned until the end of the day after use and the paste of spices were touched with unclean hands too.

Comparatively, the microbial count of restaurants of site $\mathrm{A}, \mathrm{E}, \mathrm{F}$ and $\mathrm{H}$ were found to be lower than the restaurants of site $\mathrm{B}, \mathrm{C}, \mathrm{D}$ and $\mathrm{G}$. This was due to the fact that, sanitary condition, personal hygiene of the employees and the handling practices were not quite good in restaurants of site B, C, D and G. The raw materials used for momo preparation were also not of higher quality in those restaurants.

This study gave the conclusion that the final steamed product both chicken and buff momo analysed showed insignificant total aerobic mesophilic count but did not show other microbiological counts such as yeasts and molds count, coliform count and staphylococcal count which may be due to the adequate steaming time and temperature required to kill all the vegetative cells. So from this study it can be concluded that the steaming or the cooking of the momo is the effective critical control point $(\mathrm{CCP})$ which if carried out for proper time and temperature can eliminate all the possible microbial hazards. The study also focuses that the personal health hygiene of the food handlers and the sound knowledge in sanitation and health hazard issues due to consumption of unhygienic foods should be well understood by these employees too. Above all, personal hygiene, handling and holding time-temperature are also the effective factors which have direct effect on microbial load of foods.

\section{Acknowledgement}

We acknowledge profound gratitude to the Department of Food Technology and Quality Control, Babarmahal for providing laboratory facilities. We are much obliged to Mr. Ishwor Subedi, Food Inspector of the same laboratory for assisting us during the sampling hours.

\section{References}

Bryan, F.L. 1981. Hazard analysis of food service operations. Food Technology. 35(2):78-87.

Collins, C.H., P.M. Lyne, and J.M.Grange. 1989. Microbiology methods. (6 $6^{\text {th }}$ edition). Butterworth \& Co., Ltd.

FDA. 2005. Food Code. DHHS/PHS/ Food and Drug Administration, Washington, DC.

Frazier, W.C and D.C. Westhoff. 2001. Food microbiology. Tata McGrow Hill.

Freese, E., N.W. Solomons and R. Gross. 1998. The microbiological safety of typical Guatemalan foods from street vendors, low-income homes and hotels. International Journal of Food Sciences and Nutrition 49(1):27-38.

Jay, J.M. 1992. Modern food microbiology. (4 $4^{\text {th }}$ edition). Van Nostrand Reinhold, New York.

Anderson, J, E. Swanson and M. Katherine. 2000. Industry prospective on the use of microbial data for HACCP validation and verification. Journal of Food Protection 63(6): 815-818.

Buchanan, J, L. Robert and R.C. Whiting. 1998. A means for linking HACCP plans and public health. Journal of Food Protection 61(11):1531-1534.

Christopher, J. 1999. Food hygienic and HACCP in the United Kingdom food industry. Practices, preparation and outlets. Journal of Food Protection 62(7): 786-792.

Peter, C., R. Rooney and R.S. Smith. 2000. Application of foodborne disease outbreak data in the development and maintenance of HACCP system. International Journal of Food Microbiology 59(3): 10:221-234.

Refai, M.K. 1979. Manuals of food quality control. Microbiological analysis. FAO, Food and Nutrition Paper 1979. 